\title{
Knowledge and Implementation of Protective Measures for Oral and Maxillofacial Injuries of Ice Hockey Players in Primary and Secondary Schools in Beijing
}

Bing Li ( $\nabla$ crystallibing@126.com )

Chinese PLA General Hospital https://orcid.org/0000-0003-4774-4587

Xue Bai

China PLA General Hospital

Hui Sun

Chinese PLA General Hospital

Chunyan Cui

Chinese PLA General Hospital

Weihong Liu

Chinese PLA General Hospital

\section{Research article}

Keywords: sports injury, oral and maxillofacial injury, protection

Posted Date: March 19th, 2021

DOI: https://doi.org/10.21203/rs.3.rs-329328/v1

License: (c) (i) This work is licensed under a Creative Commons Attribution 4.0 International License.

Read Full License 


\section{Abstract}

Background: There is little information regarding knowledge and implementation of sports-related oral and maxillofacial injury prevention measures of ice hockey players in primary and secondary schools. Thus, we investigated methods to improve the safety of juvenile ice hockey players in Beijing and reduce the incidence of oral and maxillofacial injuries, including tooth avulsions, tooth fractures, and jaw fractures.

Methods: Using a convenience sampling method, we obtained consent from young ice hockey players from five primary and secondary schools and six special sports training institutions in Beijing; we administered a total of 280 questionnaires.

Results: Only $12.50 \%$ of respondents reported wearing mouth guards during ice hockey; $62.50 \%$ of respondents reported never wearing a mouth guard; $43.58 \%$ did not know the risk of sports-related oral injury. Not understanding the necessity of wearing teeth protection was the most common reason reported why athletes do not wear protective gear (89.64\%). Inconsistent behaviour among teammates $(67.14 \%)$ was the psychological factor related to refusal to wear the mouth guard. Wearing discomfort (34.33\%) and communication influence (33.14\%) were also mentioned; $77.14 \%$ of the parents reported that the formulation and enforcement of the relevant regulatory agencies' standards were important to encourage young athletes to wear protective gear.

Conclusion: Young ice hockey players in Beijing lack knowledge of sports-related oral injuries and effective protective measures, despite the high risks. The most effective way to improve compliance is to draw up and enforce the Ice Hockey Association's relevant standards and the coach's guidance.

\section{Background}

The incidence of sports injury has increased as participation in youth sports increases, and the length of training time extends. The incidence of sports injury is higher in antagonistic sports due to the close even indirect physical contact between the athletes. The National Federation of High Schools and the University Sports Association require wearing a mouth guard in hockey, rugby, ice hockey, lacrosse, and other sports [1-2]. According to the statistics of soccer sports injuries by the national electronic injury monitoring system of the United States in $2001,175,000$ people in the United States are injured playing football every year, of which $43 \%$ are 8 to 14 years old; $30 \%$ of the injuries are oral and maxillofacial injuries, including tooth avulsions, tooth fractures, and jaw fractures [3-6]. Several studies have shown that dental protectors in sports can significantly reduce oral and maxillofacial injuries [7-9]. The American Dental Association and the American Society of Pediatric Dentistry also recommend using dental protectors in competitive sports. At present, China's youth participate in more aggressive sports, including football, basketball, ice hockey, rugby, baseball, hockey, and others [10]. However, there is no large sample statistical data of the injury caused by these sports, and there is little mention of wearing of tooth guards during sports. 
Using a questionnaire, we investigated primary and secondary school students who participated in ice hockey, hoping to understand the current situation of oral sports protection of primary and secondary school students in our city, and to analyse causes and countermeasures, to reduce the occurrence of sports injuries of Chinese teenagers and to promote their healthy growth.

\section{Methods}

A questionnaire was distributed to the players from ten primary and secondary schools in Beijing and 13 special sports training institutions using convenience sampling.

\section{Questionnaire design}

As a result of a literature review, we learned about sports injury prevention experience and problems outside of China. In the context of China's national conditions, we considered ten problems related to the implementation of tooth protection measures in primary and secondary school students in sports.

\section{Ethical approval and consent to participate}

The ethics committee has approved this study of the Chinese PLA General Hospital, and the committee's reference number is 20180454 . The survey content does not investigate the personal privacy of the interviewees. The interviewees signed paper informed consent forms before the investigation began.

\section{Questionnaire distribution}

Using a convenience sampling method, through a network query, recommendations from friends, and other methods, we contacted principals of ten primary and secondary schools and 13 special sports training institutions in Beijing. We explained the purpose, method, and significance of the study. Finally, with the consent of five primary and secondary schools and six special sports training institutions, athletes and parents of primary and secondary school students participating in ice hockey in their schools and institutions were invited to participate in the survey. Based on the principle of voluntary participation, parents of athletes were asked to fill in the questionnaire according to their sports experiences.

\section{Quality control}

Two researchers explained the content of the questionnaire at the point of contact, assisted the parents in completing the questionnaire, and ensured that the questions' meanings were understood accurately and that the answers were complete.

\section{Data analysis}

Excel (version 15.11.2, Microsoft, USA)was used for data entry, and Stata statistical software (version 14.2, StataCorp, USA) was used to conduct a descriptive analysis of the data using a chi-square test. 


\section{Results}

\section{Object of studies}

A total of 280 athletes participated in the survey, for a participation rate of $54 \%$, including 213 males and 63 females. The average age was $11.47 \pm 3.54$ years (Table 1 ).

Table 1

Athletes' backgrounds

\begin{tabular}{|lll|}
\hline Items & & \multicolumn{1}{c|}{$\begin{array}{c}\text { Distribution } \\
\text { (Percentage) }\end{array}$} \\
\hline Age & male & $11.47 \pm 3.54$ \\
\hline Time for ice hockey & female & $213(76.07 \%)$ \\
& $<1$ year & $67(23.93 \%)$ \\
& $1-2$ years & $53(18.93 \%)$ \\
& $2-5$ years & $68(24.29 \%)$ \\
\hline $\begin{array}{l}\text { Previous mouth } \\
\text { injuries }\end{array}$ & $\begin{array}{l}\text { Injury of skin and mucosa around the lip and } \\
\text { mouth }\end{array}$ & $74(26.43 \%)$ \\
& Tooth defect & $85(30.36 \%)$ \\
\hline $\begin{array}{l}\text { *There was one case of orthodontic fixator loosening, one case of lip swelling, and one case of } \\
\text { gingival bleeding. }\end{array}$ & $\begin{array}{l}\text { Tongue bite } \\
\text { Others* }\end{array}$ & $8(2.86 \%)$ \\
\hline
\end{tabular}

\section{Investigation on wearing and implementation of tooth guard}

According to the survey, only $12.50 \%$ of teenagers often wear tooth guard in ice hockey, and $9.64 \%$ of players only wear them in formal competitions. A total of $62.50 \%$ reported never having worn a mouthguard. 
Table 2

Implementation of the tooth guard

\begin{tabular}{|lllllll|}
\hline Groups & Cases & $\begin{array}{l}\text { Number of } \\
\text { students } \\
\text { always } \\
\text { wearing } \\
\text { tooth guard }\end{array}$ & $\begin{array}{l}\text { Number of } \\
\text { students } \\
\text { often } \\
\text { wearing } \\
\text { tooth guard }\end{array}$ & $\begin{array}{l}\text { Number of } \\
\text { students only } \\
\text { wearing tooth } \\
\text { guard in official } \\
\text { competition }\end{array}$ & $\begin{array}{l}\text { Number of } \\
\text { students } \\
\text { seldom } \\
\text { wearing } \\
\text { tooth guard }\end{array}$ & $\begin{array}{l}\text { Number of } \\
\text { students } \\
\text { never } \\
\text { wearing } \\
\text { tooth guard }\end{array}$ \\
\hline $\begin{array}{l}\text { Primary } \\
\text { school }\end{array}$ & 188 & 0 & $15(7.98 \%)$ & $10(5.32 \%)$ & $18(9.56 \%)$ & 155 \\
\hline $\begin{array}{l}\text { Junior } \\
\text { middle } \\
\text { school }\end{array}$ & 55 & 0 & $102.44 \%)$ & $28(50.91 \%)$ & $12(21.80 \%)$ \\
\hline $\begin{array}{l}\text { High } \\
\text { school }\end{array}$ & 37 & 0 & $(18.18 \%)$ & $5(9.1 \%)$ & & \\
\hline Total & 280 & 0 & 10 & $12(32.43 \%)$ & $8(21.62 \%)$ & $8(21.62 \%)$ \\
\hline
\end{tabular}

\section{Athletes' and parents' understanding of tooth protection in sports}

Among the participants, $2.14 \%$ of the respondents said that they knew the risk of oral injury in ice hockey, and $54.29 \%$ of the respondents said that they had only heard about it but did not know much about it; $12.14 \%$ of the respondents did not know the existence of sports injury risk, and $31.43 \%$ of the respondents reported believing sports injuries would not happen.

A total of $47.86 \%$ of the respondents reported knowing that they needed to wear tooth protectors in ice hockey matches, according to notices issued by the ice hockey association, and $22.14 \%$ of the parents learned about it by browsing sports or shopping websites. Only 10 (3.57\%) were obtained through dental guidance. Eight had a history of oral injury, and two parents reported that they were dentists. A total of $8.57 \%$ of the respondents reported never having obtained any relevant information. If more relevant information was needed, the most popular way for parents to obtain information was through the coach's guidance $(41.78 \%)$ or the ice hockey association publicity $(33.92 \%)$.

Some parents reported believing that social publicity (12.14\%) and dentist guidance (10.36\%) were the most effective ways to spread information. Only four parents $(1.43 \%)$ reported believing that the mutual influence between athletes and parents' recommendation is the best way to spread information (Table 3). 
Table 3

Knowledge on the part of parents of young athletes regarding sports-related oral injury and protective measures

\begin{tabular}{|c|c|c|c|}
\hline Questions & Options & Numbers & Percentage \\
\hline \multirow{4}{*}{$\begin{array}{l}\text { Do you know about sports-related oral } \\
\text { injury }\end{array}$} & Yes, I know it very well & 6 & $2.14 \%$ \\
\hline & Yes, but I don't know much & 152 & $54.29 \%$ \\
\hline & Never heard of it & 34 & $12.14 \%$ \\
\hline & $\begin{array}{l}\text { Yes, but I don't think that will } \\
\text { happen }\end{array}$ & 88 & $31.43 \%$ \\
\hline \multirow{6}{*}{$\begin{array}{l}\text { How do you get the information about } \\
\text { wearing the mouthguard in sports } \square\end{array}$} & Coach's advice & 54 & $19.28 \%$ \\
\hline & Notice of sports association & 134 & $47.86 \%$ \\
\hline & Media publicity & 62 & $22.14 \%$ \\
\hline & Recommended by teammates & 44 & $15.71 \%$ \\
\hline & Guidance from dentists & 10 & $3.57 \%$ \\
\hline & Never heard of it & 24 & $8.57 \%$ \\
\hline \multirow{5}{*}{$\begin{array}{l}\text { Which channel would you like to know } \\
\text { more about it? }\end{array}$} & Dentist & 29 & $10.36 \%$ \\
\hline & Coach & 117 & $41.78 \%$ \\
\hline & Hockey association & 95 & $33.92 \%$ \\
\hline & Social media & 34 & $12.14 \%$ \\
\hline & $\begin{array}{l}\text { Communication between } \\
\text { team members and parents }\end{array}$ & 4 & $1.43 \%$ \\
\hline
\end{tabular}

\section{Influencing factors and obstacles to wearing tooth guards}

A total of $89.64 \%$ of the parents thought that Don't understand the necessity was the most important reason why the athletes did not wear the tooth protector. Inconsistent behaviour among other teammates $(67.14 \%)$, discomfort (34.33\%), image changed caused by wearing $(17.50 \%)$, and affect communication (33.21\%) are also important reasons for athletes not to wear tooth guards. Only $2.85 \%$ of the athletes reported obvious discomforts such as suffocation and nausea.

A total of $77.14 \%$ of the parents reported believing that the formulation and enforcement of the standards of the relevant regulatory agencies were important for encouraging young athletes to wear protective gear, and the coaches' supervision was also an effective method (54.64\%). Over $30 \%$ of parents reported believing that parents' supervision and teammates' influence can help promote compliance (Table 4). 
Table 4

Influencing factors and obstacles to wearing tooth guards

\begin{tabular}{|c|c|c|c|}
\hline Questions & Options & Numbers & Percentage \\
\hline \multirow{8}{*}{$\begin{array}{l}\text { The reasons hindering } \\
\text { young athletes from } \\
\text { wearing a mouth guard }\end{array}$} & \multirow{2}{*}{$\begin{array}{l}\text { Don't understand the necessity of tooth } \\
\text { protection }\end{array}$} & 251 & $89.64 \%$ \\
\hline & & 188 & $67.14 \%$ \\
\hline & \multirow{2}{*}{$\begin{array}{l}\text { Don't want to be special } \\
\text { Slightly uncomfortable when wearing, such } \\
\text { as foreign body feeling in the mouth, } \\
\text { troublesome to wear }\end{array}$} & 97 & $34.33 \%$ \\
\hline & & 93 & $33.21 \%$ \\
\hline & \multirow{2}{*}{ Wearing affects language communication } & 49 & $17.50 \%$ \\
\hline & & 15 & $5.36 \%$ \\
\hline & Affect appearance after wearing & \multicolumn{2}{|c|}{ The high price of tooth guard } \\
\hline & \multicolumn{3}{|l|}{$\begin{array}{l}\text { Obvious discomforts when wearing, such } \\
\text { as suffocation, nausea, and other } \\
\text { symptoms }\end{array}$} \\
\hline \multirow{7}{*}{$\begin{array}{l}\text { How to improve the } \\
\text { wearing rate of tooth guard }\end{array}$} & \multirow{2}{*}{$\begin{array}{l}\text { Sports associations set standards and } \\
\text { enforce them }\end{array}$} & 216 & $77.14 \%$ \\
\hline & & 153 & $54.64 \%$ \\
\hline & Coach urges wearing & 104 & $37.14 \%$ \\
\hline & The interaction between teammates & 90 & $32.14 \%$ \\
\hline & Parents urge wearing & 18 & $6.43 \%$ \\
\hline & To improve the comfort of tooth guard & & \\
\hline & To reduce protection costs & 2 & $0.11 \%$ \\
\hline
\end{tabular}

\section{Discussion}

\section{Oral protection measures should be taken for teenagers to participate in ice hockey}

With the 2022 Beijing Winter Olympic Games approaching, the implementation outline for 'driving 300 million people to participate in ice and snow sports' issued by the National Ministry of Sports in 2018 came into effect. Ice and snow sports are becoming increasingly popular. One of the sports promotion programs for young people, the General Administration of the People's Republic of China, issued guidelines for the ice hockey program jointly with the Ministry of Education of the People's Republic of China. However, there was no direct relationship between the increase in ice hockey participation and participants' awareness of sports injuries.

Ice hockey is one of the fiercest antagonistic sports, and the incidence of sports injuries is high. Oral injury, especially dental injury, has a long-term effect on injured athletes' function; there are also external 
and psychological effects on injured athletes. In recent years, athletes participating in antagonistic sports have paid more attention to oral protection in sports. According to a national electronic injury monitoring system of the United States in 2001, 175000 people were injured playing football every year, of which $43 \%$ were 8 to 14 years of age. A total of $30 \%$ of the injuries were oral and maxillofacial injuries, including tooth avulsions, tooth fractures, and jaw fractures $[11,12]$. Because ice hockey allows a certain degree of collisions, the risk of sports-related injuries is higher. In the present study, 20 individuals reported periodontal injuries (7.14\%), and eight reported tooth injuries $(2.86 \%)$.

Tooth guards are thought to be effective oral protective devices that reduce the impact force in sports via a significant buffering effect; they reduce the incidence of tooth fractures, tooth avulsions, jaw fractures, and other injuries [5]. The National Federation of high schools and the University Sports Association both require mouthguards in hockey, rugby, ice hockey, and lacrosse [1, 6]. The American Dental Association and the American Society of Pediatric Dentistry also recommend using dental protectors for athletes participating in competitive sports [2]. China's 2018 Haidian District Youth Ice Hockey League's competition requirements clearly state that participants must wear dental protectors. However, in the survey, only $22.17 \%$ of the athletes reported wearing tooth guards, and $62.5 \%$ of the athletes reported never having worn one. One investigation in the United States was not optimistic; Collins et al. surveyed young athletes who participated in basketball, football, and other aggressive sports in 21 middle schools [13]. A total of $22.6 \%$ of the athletes never knew that they needed to wear tooth protectors, and only $12.3 \%$ often wear them or used to wear them in sports. Chukwudi et al. performed a survey of Nigeria in which $19.16 \%$ of young athletes reported wearing tooth guards [14]. It can be seen that, although tooth protectors are known to protect teeth, it remains difficult to promote their use among young athletes. To improve young people's safety in antagonistic sports, we should further understand the difficulties and obstacles they encounter in self-protection to provide targeted help and guidance.

\section{Young ice hockey players and their parents lack knowledge of sports-related oral injury}

Although the mouthguard wearing rate in this survey was not high, more than half of the respondents reported knowing that athletes are at risk of oral injury; however, they reported not knowing much about it. A total of $43.58 \%$ of the respondents reported not knowing that the injuries could occur and even believed that oral injury would not occur. A total of $48.10 \%$ of the respondents reported knowing that they need to wear tooth protectors in ice hockey matches because of notices issued by the ice hockey association. Most of these notices came from the ice hockey association's requirements regarding protective gear in competition but do not mention the necessity or correct method of wearing tooth protectors. Only $18.31 \%$ of the respondents' information came from coaches' guidance. It can be seen that the ice hockey coach's understanding of the mouthguard is not profound. Although modern medicine has been paying increasing attention to oral health care, oral health professionals, and social health propaganda do not provide Titles in BMC Oral Health appear to be in sentence case (only first words, proper nouns, and acronyms capitalized health guidance for athletes. Among the respondents who reported being guided by stomatologists, eight reported oral injuries and learned relevant information during treatment. Two 
parents of athletes reported that their occupation was stomatologist. Also, $8.31 \%$ of the respondents had never obtained any relevant information.

Most of the respondents expressed their desire to know the relevant information through ice hockey coaches or sports associations' publicity and requirements. Because the respondents reported believing that they should understand the risks associated with ice hockey, athletes contact them most, it is easier for them to obtain information. The athletes have higher compliance with coaches' guidance. Only $10.23 \%$ of the respondents chose oral health care personnel as the best way to obtain information, even lower than social media. This may indicate that China's medical resources remain deficient at present, and the focus of dental specialists remains focused on the treatment of oral diseases. Lack of community service, inability to provide routine oral examinations, prevention, and treatment of potential oral diseases, and other health care services all suggest that there remains a long way to go to achieve ideal 'national oral health.' Respondents reported believing that it takes a long time to wait in line to listen to stomatologists or nurses' professional guidance, and doctors often did not have time to provide detailed health guidance for patients. Without oral diseases, there is no opportunity to meet dental professionals; therefore, it is difficult to obtain health guidance. To achieve national oral health, dental specialist medical staff must go deep into community hospitals to ensure that the community can obtain convenient oral health guidance, regular examinations, and other basic services.

\section{How to improve the rate of wearing tooth guards among Chinese teenagers}

To further study the tooth guard wearing rate among teenagers in China, we investigated the factors that affect the wearing of dental protectors. According to our previous analysis, $89.64 \%$ of the parents stated that this was the most important reason why the athletes did not wear tooth protectors. This is consistent with the survey results of Chukwudi et al. [14] who found a significant correlation between compliance with wearing oral protective equipment and the athletes' knowledge of the risk and consequences of oral injury. We believe that our athletes lack the channels to obtain information regarding oral protective equipment and that oral health education related to sports is very important.

A total of $67.14 \%$ of the respondents reported not wanting to be different from others because of wearing the mouthguard. Another $17.50 \%$ of respondents reported unwillingness to accept the change of the image entailed in wearing a mouthguard. The discomfort and communication difficulties after wearing the mouthguard also reduced compliance. However, in ice hockey, helmets, padding, and other protective equipment are very common, and there is no movement resistance. Therefore, the perfect implementation of the relevant regulations of competition requirements and sports safety are the best measures to promote the use of teeth guards. A total of $77.14 \%$ of the parents reported believing that the formulation and enforcement of the relevant regulatory agencies' standards were important measures to encourage young athletes to wear mouthguards. Coach supervision was reported to be the most important (54.64\%). At present, many countries require coaches of antagonistic sports to receive safety education related to injuries and to master emergency treatment interventions for tooth avulsions, tooth fractures, and other 
injuries. The coaches must pass a strict examination before they can obtain the qualification. This can reduce the impact of sports-related injuries and the adverse consequences of injury worthy of our learning and reference.

Future efforts of oral medical professionals should focus on the comfort of tooth guards and reduce the costs of wearing them. There are three main types of tooth guard sleeves: The first type is the ordinary tooth guard. It is preformed and is ready to wear. It is inexpensive; however, it is uncomfortable. It causes pain, nausea, dyspnoea, and other symptoms. The second type is the heated and occlusive type of tooth guard, worn for the first time after being heated in water, to make it suitable for various people to wear. This kind of tooth guard is the most popular one; it is more comfortable than the ordinary one. However, due to its substantial thickness, it may affect normal communication in sports. There are also uncomfortable symptoms, such as foreign body sensation. The third type is the custom-made tooth guard, which doctors and technicians make based on imaging techniques. It is characterized by accurate retention and stable wearability. It can prevent oral injury while ensuring comfort and durability. However, athletes need to go to clinics often and cooperate with doctors during the customization process; this requires a long time and is expensive. Therefore, it is of great significance to develop a tooth guard characterized by strong resistance and ease of wearing.

\section{Conclusions}

Ice hockey is an intensely competitive sport, and the risk of oral injury is high. It is necessary to wear effective sports protective equipment such as tooth guards. The youth ice hockey players in Beijing lack an understanding of sports-related oral injuries and effective protection measures. The most effective way to improve compliance with ice hockey association recommendations is to draw up the relevant standards and coaches' guidance regarding wearing protective gear. Oral health care personnel should promote the oral health of all people. Currently, oral health care in the community has substantial room for improvement.

\section{Abbreviations}

USA-United States of America

\section{Declarations}

\section{Ethical approval and consent to participate:}

The ethics committee has approved this study of the Chinese PLA General Hospital, and the committee's reference number is 20180454 . The survey content does not investigate the personal privacy of the interviewees. The interviewees signed the paper informed consent forms before the investigation began.

\section{Consent for publication:}


Not applicable

\section{Availability of supporting data:}

The datasets used and/or analysed during the current study available from the corresponding author on reasonable request.

\section{Competing interests:}

The authors declare that they have no competing interests.

\section{Funding:}

Not applicable

\section{Authors' contributions:}

LB designed the questionnaire and was a major contributor in writing the manuscript. BX and SH analysed and interpreted the data. CC and LW completed the ethical argumentation and informed consent. All authors read and approved the final manuscript.

\section{Acknowledgments:}

Not applicable

\section{References}

1. National Federation of State High School Associations. Sports Medicine Handbook. $4^{\text {th }}$ ed. Indianapolis, IN: National Federation of State High School Associations. 2011.

2. Klossner D. 2013-14 NCAA Sports Medicine Handbook. 24 ${ }^{\text {th }}$ ed. Indianapolis, IN: The National Collegiate Athletics Association. 2013.

3. Ferrari $\mathrm{CH}$, Ferreria de Mederios JM. Dental trauma and level of information: mouthguard use in different contact sports. Dent Traumatol. 2002;8:144-147.

4. Yamada T, Sawaki Y, Tomida S, Tohnai I, Ueda M. Oral injury and mouthguard usage by athletes in Japan. Endod Dent Traumatol. 1998;14:84-87.

5. Kvittem B, Hardie NA, Roettger M, Conry J. Incidence of orofacial injuries in high school sports. J Public Health Dent. 1998;58:288-293.

6. Sane J, Ylipaavalniemi P. Maxillofacial and dental soccer injuries in Finland. Br J Oral Maxillofac Surg. 1987;25:383-90.

7. Labella CR, Smith BW, Sigurdsson A. Effect of mouthguards on dental injuries and concussions in college basketball. Med Sci Sports Exerc. 2002;34:41-44. 
8. Maestrello-deMoya MG, Primosch RE. Orofacial trauma and mouth-protector wear among high school varsity basketball players. ASDC J Dent Child. 1989;56:36-39.

9. Flanders RA, Bhat M. The incidence of orofacial injuries in sports: a pilot study in Illinois. J Am Dent Assoc. 1995;126:491-496.

10. American Academy of Pediatric Dentistry. Mouth protectors. http://www.aapd.org/publications/brochures/mouthpro.asp/ accessed 25 September 2019.

11. Ranalli DN. Prevention of sports-related traumatic dental injuries. Dent Clin North Am. 2000;44:3551.

12. Yamada T, Sawaki Y, Tomida S, Tohnai I, Ueda M. Oral injury and mouthguard usage by athletes in Japan. Endod Dent Traumatol. 1998;1:84-87.

13. Pribble JM, Maio RF, Freed GL. Parental perceptions regarding mandatory mouthguard use in competitive youth soccer. Inj Prev. 2004;10:159-162.

14. Neeraja G, Bharadwaj S, Shah K, Subramaniam P. Knowledge, attitude, and practices regarding orofacial injuries and oro-facial protective devices among physical instructors in Bangalore. J Int Oral Health. 2014;6:1-6.

\section{Supplementary Files}

This is a list of supplementary files associated with this preprint. Click to download.

- Questionnaire.docx 